\title{
Multichannel Intraluminal Impedance and pH Monitoring: A Step Towards Pediatric Reference Values
}

\author{
Francesco Cresi, ${ }^{1}$ Elena Andrea Cester, ${ }^{1}$ Silvia Salvatore, ${ }^{2}$ Domenico Umberto De Rose, ${ }^{3 *}$ Antonio Ripepi, ${ }^{2}$ Anna Maria Magistà, ${ }^{4}$ \\ Claudia Fontana, ${ }^{4}$ Elena Maggiora, ${ }^{1}$ Alessandra Coscia, ${ }^{1}$ Ruggiero Francavilla, ${ }^{4}$ and Fernanda Cristofori ${ }^{4}$
}

${ }^{\prime}$ Neonatology and Neonatal Intensive Care Unit, Department of Public Health and Pediatrics, University of Turin, Turin, Italy; ${ }^{2}$ Pediatric Department, Università dell'Insubria, Varese, Italy; ${ }^{3}$ Department of Pediatrics, Fondazione Policlinico Universitario "A. Gemelli" IRCCS Università Cattolica del Sacro Cuore, Rome, Italy; and ${ }^{4}$ Department of Pediatrics, Aldo Moro University of Bari - Giovanni XXIII Hospital, Bari, Italy

\section{Background/Aims}

Combined multichannel intraluminal impedance and $\mathrm{pH}$ monitoring $(\mathrm{MII} / \mathrm{pH})$ is considered the most accurate test to detect gastroesophageal reflux (GER), however lacking reference values. We aim to determine reference values for the pediatric population and to correlate these values with age and postprandial/fasting period.

\section{Methods}

We evaluated MII/pH traces from patients (newborns, infants, and children) admitted to 3 Italian hospitals and who underwent MII/ $\mathrm{pH}$ for suspected GER disease. Patients with MII/pH traces that showed significant symptom-reflux associations and/or a pathological reflux index (>6\% for newborns and infants, > 3\% for children) were excluded. Traces were analysed in their entirety, and in the postprandial period (first hour after a meal) and the fasting period (the following hours before the next meal) separately.

\section{Results}

A total of 195 patients (46 newborns, 83 infants, and 66 children) were included. Age positively correlated with frequency of acidic GER events $(r=0.37, P<0.05)$ and negatively associated with weakly acidic GER events $(r=0.46, P<0.05)$.

\section{Conclusions}

This study describes the distribution of MII/pH values in a pediatric population with normally acidic GER exposure and no significant association between GER events and symptoms. These MII/pH values may be used as reference values in clinical practice for a corrected GER disease diagnosis in the pediatric population.

(J Neurogastroenterol Motil 2020;26:370-377)

Key Words

Child; Esophageal pH monitoring; Gastroesophageal reflux; Infant; Reference values

Received: August 31, 2019 Revised: February 12, 2020 Accepted: February 20, 2020

(a) This is an Open Access article distributed under the terms of the Creative Commons Attribution Non-Commercial License (http://creativecommons. org/licenses/by-nc/4.0) which permits unrestricted non-commercial use, distribution, and reproduction in any medium, provided the original work is properly cited.

*Correspondence: Domenico Umberto De Rose, MD Department of Pediatrics, Fondazione Policlinico A. Gemelli IRCCS - Università, Cattolica del Sacro Cuore, Largo A. Gemelli 8, 00168 Rome, Italy Tel: +39-6-30154475, Fax: +39-6-3052751, E-mail: derosedomenicoumberto@gmail.com 


\section{Introduction}

Gastroesophageal reflux (GER) is a common phenomenon in infants and children. ${ }^{1}$ Clinical diagnosis of GER is laborious, as symptoms in infants and young children are not specific and overlap with a wide spectrum of different disorders. However, proper evaluation of GER events is important to identify patients with GER disease (GERD) and to avoid the inappropriate use of acid-suppressors, which are often prescribed on a clinical or ownexperience basis. $^{2-6}$

Combined multichannel intraluminal impedance and $\mathrm{pH}$ monitoring $(\mathrm{MII} / \mathrm{pH})$ provides a detailed description of esophageal events and is considered the most accurate test to detect GER in infants and children, although its use in clinical practice is not widespread. ${ }^{7,8}$ Indeed, there are limitations to $\mathrm{MII} / \mathrm{pH}$, including the cost of the equipment, the need to carry out 24-hour monitoring sessions with a nasogastric probe, the experience needed to accurately analyse $\mathrm{MII} / \mathrm{pH}$ traces, and the inter- and intra-observer variability of visual compared to automated analysis. ${ }^{9}$

Nevertheless, in the latest decade, $\mathrm{MII} / \mathrm{pH}$ data has led to improvements in our knowledge of GER pathophysiology and has helped assess the relationship between GER events and symptoms. $^{10-13} \mathrm{MII} / \mathrm{pH}$ can detect all types of GER events, and these events can be classified according to concomitant changes in the intra-esophageal $\mathrm{pH} .{ }^{7,14}$ Furthermore, $\mathrm{MII} / \mathrm{pH}$ allows us to analyze the relationship between GER events and symptoms through methods such as the symptom index (SI), symptom sensitivity index, and symptom association probability (SAP) index.

Among $\mathrm{MII} / \mathrm{pH}$ parameters, the most known is the reflux index (RI). Other variables that can be derived from MII-channel recordings are GER frequency, duration, and proximal extent, and the bolus exposure index (BEI). ${ }^{15}$ While the cut-off for RI has been reported, ${ }^{1}$ reference values for other MII parameters in the pediatric population are still uncertain ${ }^{7}$ and could be inappropriate as they are derived from adult populations. ${ }^{16-18}$ As $\mathrm{MII} / \mathrm{pH}$ is an invasive test, for ethical reasons it cannot be performed on healthy infants and children, making it challenging to obtain traditional reference values, ie, from a normal, healthy population, for $\mathrm{MII} / \mathrm{pH}$ parameters. One way to overcome this problem is to consider a large, symptomatic population with negative $\mathrm{MII} / \mathrm{pH}$ results (ie, results that do not indicate GERD). This population can be defined as a "reference" population because of its negative $\mathrm{MII} / \mathrm{pH}$ results, even though it is not exactly "normal," because it is symptomatic.

Indexes of the association between GER events and symptoms currently have the same definition and values for all ages and can be helpful to classify a $\mathrm{MII} / \mathrm{pH}$ trace as pathological or normal. ${ }^{7-19}$ In the last 10 years, some authors ${ }^{19-21}$ have described reference ranges for infants and children, but unfortunately, the uniqueness of the population recruited, the small sample size, or the lack of newborns younger than 3 weeks limited their use. The aim of the present study is to determine $\mathrm{MII} / \mathrm{pH}$ reference values for the neonatal and pediatric population and to correlate these values with age and postprandial/fasting period.

\section{Materials and Methods}

In this multicentric retrospective observational study we evaluated $\mathrm{MII} / \mathrm{pH}$ traces from patients who underwent $\mathrm{MII} / \mathrm{pH}$ for suspected GERD ${ }^{22}$ (symptoms such as weight loss or poor weight gain, irritability, ruminative behavior, heartburn or chest pain, hematemesis, dysphagia, odynophagia, wheezing, stridor, cough, and hoarseness) at 3 Italian hospitals.

Indications, methodology and interpretation used for the MII/ $\mathrm{pH}$ studies were the same in all centers, according Italian guidelines of the Italian Society of Pediatric Gastroenterology, Hepatology, and Nutrition (SIGENP) working group. ${ }^{22}$

Patients were enrolled in the study if they met the following inclusion criteria: (1) a valid $\mathrm{MII} / \mathrm{pH}$ trace for a minimum 21 hours, of which a minimum of 16 hours excluding artifacts and meals; (2) absence of therapies with effects on GER for at least 1 week before $\mathrm{MII} / \mathrm{pH}$; (3) absence of congenital heart defects, infectious, genetic, metabolic, and neurological diseases; and (4) being fed orally without any tube feeding.

All newborns, infants, and children with a pathological RI $(>3 \%$ for children and $>6 \%$ for newborns and infants) and/or a significant association between GER events and symptoms (expressed as SI $\geq$ $50 \%$ and SAP $\geq 95 \%$ ), according to European Society for Pediatric Gastroenterology, Hepatology, and Nutrition (ESPGHAN) guidelines and Mousa's study, ${ }^{1,20}$ were excluded from the study.

During $\mathrm{MII} / \mathrm{pH}$ recording newborns were kept supine and received breast milk or formula from a feeding bottle every 4 hours (thickened formulas were excluded).

Parents of included patients provided written informed consent to undergo $\mathrm{MII} / \mathrm{pH}$. The study protocol conforms to the ethical guidelines of the 1975 Declaration of Helsinki (6th revision, 2008) as reflected in a priori approval by the institution's human research committee and it was approved by the Local Committee for Health Research Ethics in Turin, Italy (No. 0046662).

Patients were classified into 3 groups by age: newborns (aged 
0-30 days), infants (aged 1-12 months), and children (1-16 years).

A single-use, age-appropriate (infant/pediatric) $\mathrm{MII} / \mathrm{pH}$ catheter (Sandhill Scientific, Highland Ranch, CO, USA) was used. Each catheter has a diameter of $2.13 \mathrm{~mm}(6.4 \mathrm{~F})$ and contains 7 impedance sensors, corresponding to 6 impedance channels and an antimony electrode sensitive to $\mathrm{pH}$ variation. The antimony electrode was calibrated with 2 different $\mathrm{pH}$ solutions $(\mathrm{pH} 4.0$ and $\mathrm{pH}$ 7.0) before each $\mathrm{MII} / \mathrm{pH}$ session. The appropriate catheter size was placed transnasally after a 3-hour fasting period. In newborns and infants, impedance channels were positioned every $1.5 \mathrm{~cm}$, whereas in children they were placed every $2 \mathrm{~cm}$, with the pH-electrode in the middle of the most distal channel, placed at the level of the second vertebra above the diaphragm. The approximate position of the probe was calculated according to Strobel's formula, ${ }^{22}$ checked radiologically, and corrected if necessary. The catheter was then connected to an exterior impedance device (Sleuth System; Sandhill Scientific) for signal processing and recording. Parents and older children were instructed to press the "event" buttons on the device in case of specific symptoms. They were also asked to complete a written diary reporting any symptoms, meal and sleeping times, and position changes (supine/upright) that occurred during $\mathrm{MII} / \mathrm{pH}$.

The $\mathrm{MII} / \mathrm{pH}$ traces were visually evaluated by a single expert operator from each center. To reduce inter-observer variability, ${ }^{9}$ all operators had similar experience and analyzed the traces with the same software (BioView Analysis, Sleuth System; Sandhill Scientific). A MII-GER event was defined as a decrease in impedance starting in the most distal channel, extending proximally over 2 or more channels, and followed by an increase in impedance back to baseline values. The duration of a GER event was defined as the time (in seconds) between its onset (50\% drop in impedance from baseline relative to nadir) and bolus exit (50\% recovery point from nadir to baseline) recorded at the distal channel. The $\mathrm{pH}$ value of each MII-GER event was defined as the nadir esophageal $\mathrm{pH}$ recorded during that event and was classified as acidic (MII-A-
GER, $\mathrm{pH}<4$ ), weakly acidic (MII-WA-GER, $4 \leq \mathrm{pH}>7$ ), or weakly alkaline (MII-WALK-GER, $\mathrm{pH} \geq 7$ ). A pH-GER event was defined as a temporary drop of the $\mathrm{pH}$ value below 4 lasting at least 5 seconds and not associated with a MII-GER event. ${ }^{14-24}$

Different $\mathrm{MII} / \mathrm{pH}$ parameters were evaluated: GER frequency, expressed as GER/hour; proximal GER frequency, ie, GER reaching the 2 most proximal MII channels, expressed as GER/ hour; bolus clearance time (BCT), expressed in seconds; BEI, defined as percentage of time in which the bolus was detected in the distal impedance channel; and RI, expressed as the percentage of time during which the distal esophagus is exposed to a $\mathrm{pH}<4$. We chose to calculate GER frequency as GER/hour to provide comparable data in all patients regardless of the duration of $\mathrm{MII} / \mathrm{pH}$. In this way, we were able to analyse $\mathrm{MII} / \mathrm{pH}$ traces in their entirety, and in the postprandial period (first hour after a meal) and the fasting period (the following hours before the next meal) separately.

Data are presented as numbers and percentages for categorical variables. Continuous variables were expressed as mean and standard deviation if normally distributed, or as median and interquartile range if normality could not be accepted. The paired sample $t$ test was used to compare values in the postprandial and fasting periods. ANOVA was used to evaluate $\mathrm{MII} / \mathrm{pH}$ variables among newborns, infants, and children. Pearson's test was used to evaluate the correlation between values of $\mathrm{MII} / \mathrm{pH}$ parameters and age. A $P$-value $<0.05$ was considered statistically significant. Statistical analyses were performed using the STAT software package for Windows, release 5.5 (StatSoft, Tulsa, OH, USA).

\section{Results}

A total of 195 patients (46 newborns, 83 infants, and 66 children) had MII-pH traces that satisfied the inclusion criteria. The 3 centers analysed 75 (37 newborns, 37 infants, and 1 child), 65 (8 newborns, 20 infants, and 37 children), and 55 traces (1 newborn,

Table 1. Characteristics of the Study Population

\begin{tabular}{lcccc}
\hline \multicolumn{1}{c}{ Characteristics } & Newborns & Infants & Children & All children \\
\hline Cases & 46 & 83 & 66 & 195 \\
Age & $18(3-30)$ day & $64(32-328) \mathrm{mo}$ & $5(1-16) \mathrm{yr}$ & $0(0-16) \mathrm{yr}$ \\
Gender & $29 \mathrm{M} / 17 \mathrm{~F}$ & $42 \mathrm{M} / 41 \mathrm{~F}$ & $33 \mathrm{M} / 33 \mathrm{~F}$ & $104 \mathrm{M} / 91 \mathrm{~F}$ \\
Time of analysis (min) & $1356(1228-1441)$ & $1232(1139-1363)$ & $1267(1191-1324)$ & $1271(1165-1370)$ \\
Meal period (min) & $67(48-100)$ & $90.5(61-134)$ & $83(59-109)$ & $81(56-121)$ \\
Postprandial (min) & $354(315-413)$ & $354(295-436)$ & $239(189-295)$ & $354(246-413)$ \\
Fasting (min) & $883.5(830-976)$ & $797(670-924)$ & $942(806-987)$ & $852(720-963)$ \\
\hline
\end{tabular}

Data are presented as number, median (range), or median (interquartile range). 


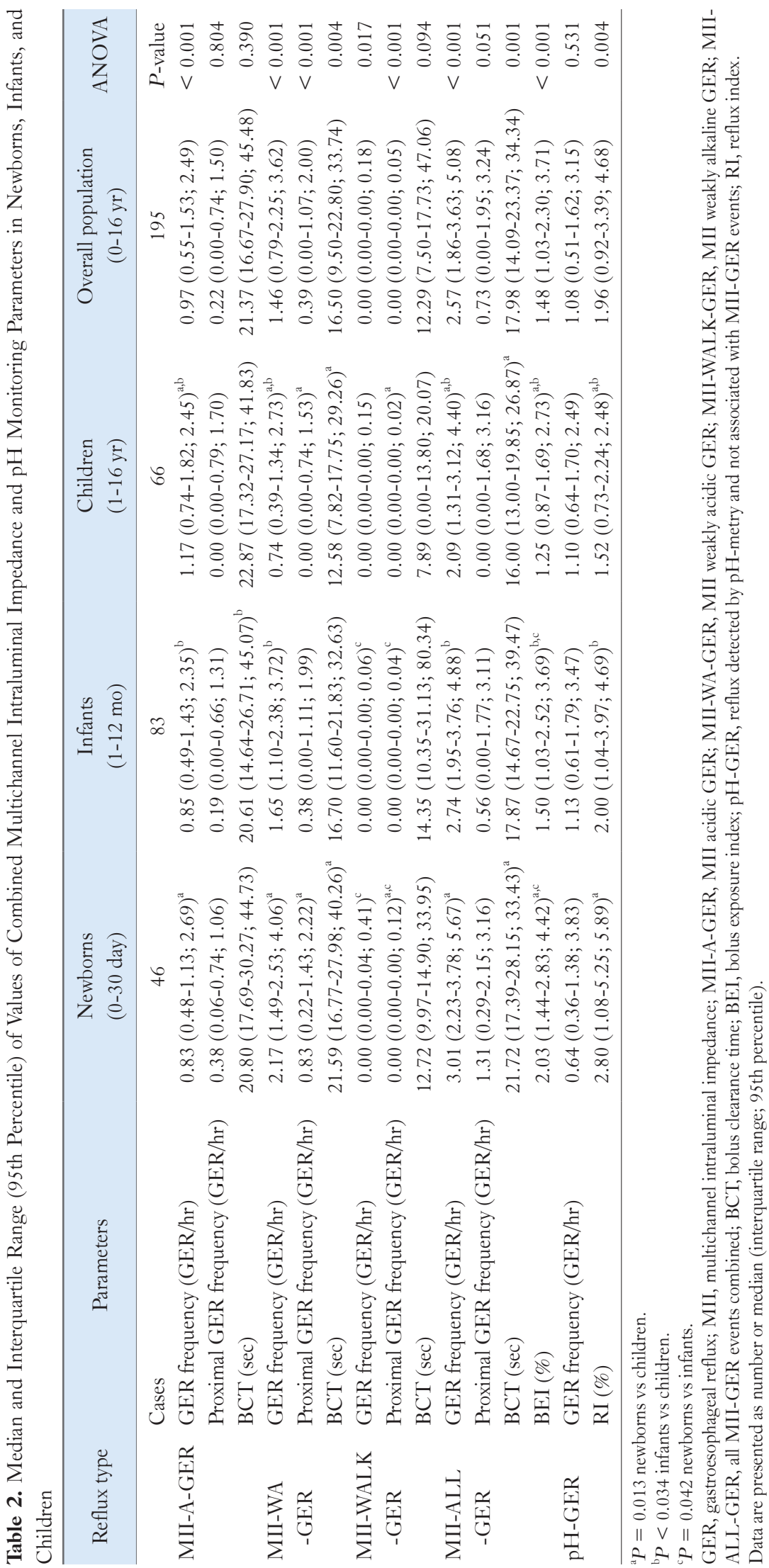


26 infants, and 28 children), respectively. Characteristics of the population and the median duration of analyzed traces are listed in Table 1.

\section{Multichannel Intraluminal Impedance Reference Values in Newborns, Infants, and Children}

The mean GER frequency, BCT, and BEI for all MII-GER events combined (MII-ALL-GER) significantly decreased from newborns to children. We found a significantly $(P<0.001)$ higher MII-A-GER frequency in children than in newborns and infants. No difference was observed in MII-A-GER BCT between the 3 groups. On the other hand, the greatest MII-WA-GER frequency was observed in newborns, with a progressive decline towards children $(P<0.001)$. Longer MII-WA-BCT was observed in newborns as compared to infants $(P=0.051)$ and children $(P<0.001)$ (Table 2). MII-WALK-GER was very rarely represented in all age groups. Pearson correlation models demonstrated a positive correlation between age and MII-A-GER $(r=0.37, P=0.039)$ and a negative correlation between age and MII-WA-GER $(r=-0.46$, $P=0.028)$.

\section{Postprandial and Fasting Periods}

We found that MII-A-GER was significantly $(P<0.002)$ more frequent in newborns during the fasting period, while MIIWA-GER was predominant in newborns and infants during the postprandial period $(P<0.001)$ (Fig. 1). In contrast, a significantly higher MII-A-GER frequency occurred in children during the postprandial period $(P<0.001)$ (Fig. 1), and a reduction of MIIWA-GER occurred during the fasting period $(P<0.001)$ (Table 3 ).
Pearson analysis revealed a positive correlation between age and MII-A-GER in the postprandial period $(r=0.30, P=0.021)$ and a negative correlation between age and MII-WA-GER in postprandial periods $(r=-0.28, P=0.031)$, and between age and MII-A-GER during fasting periods $(r=-0.33, P=0.042)$. A positive correlation was also demonstrated between MII-WA-GER frequency during the fasting period and MII-A-GER frequency during both the postprandial $(r=0.40, P=0.043)$ and the fasting period $(r=0.20, P=0.029)$. MII-WA-GER frequency during the postprandial period strongly correlated with MII-A-GER frequency during the fasting period ( $r=0.60, P=0.014)$ (Fig. 2).

\section{Discussion}

In the present study, we provide reference values for $\mathrm{MII} / \mathrm{pH}$ parameters for pediatric patients, including newborns. These results reinforce the current scientific knowledge on this topic, ${ }^{20,21}$ adding data on newborns, with advantages for clinicians reporting MII/ $\mathrm{pH}$ pediatric traces.

Our study sample of newborns, infants, and children referred to $\mathrm{MII} / \mathrm{pH}$ for suspected GERD, is one in which participants showed neither a significant association between GER events and symptoms, nor a pathological RI on $\mathrm{MII} / \mathrm{pH}$ tracings. As such, they might be considered the most representative of a healthy population. In order to align our results with ESPGHAN and the North American Society for Pediatric Gastroenterology, Hepatology, and Nutrition (NASPGHAN) guidelines ${ }^{1}$ and 2 previously studies on pediatric reference data, ${ }^{19,20}$ we only included patients with negative SI and SAP and a normal RI, ${ }^{1}$ using exactly the same
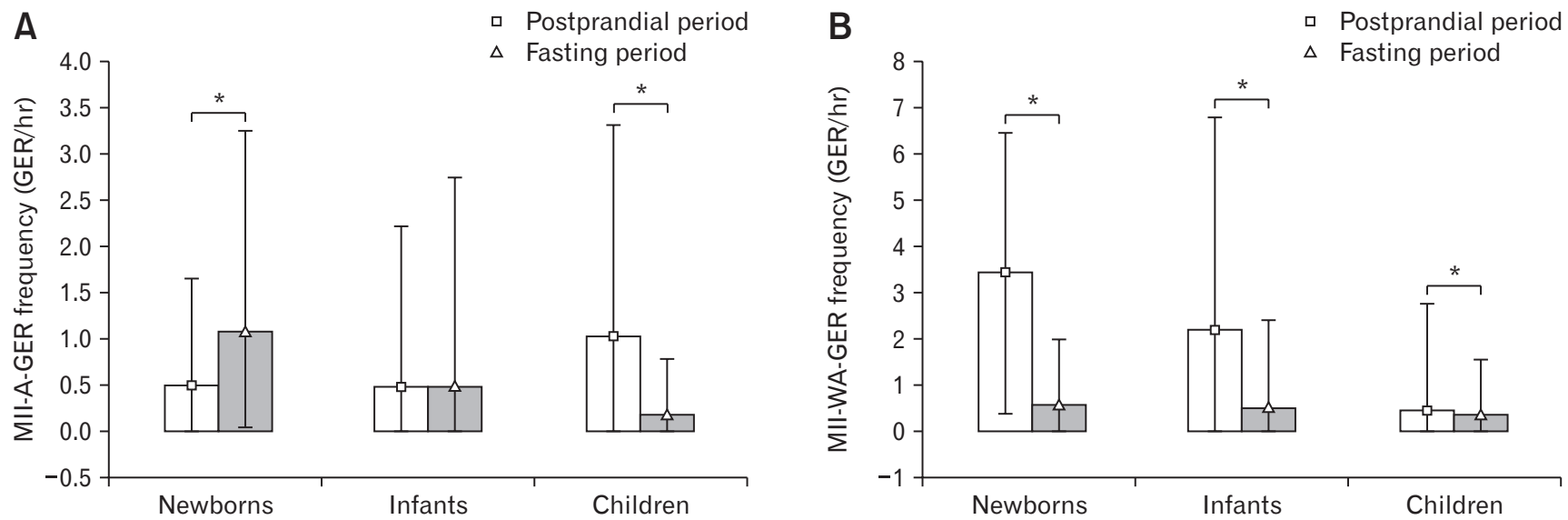

Figure 1. Differences in multichannel intraluminal impedance acidic gastroesophageal reflux (MII-A-GER) frequency (A) and multichannel intraluminal impedance weakly acidic gastroesophageal reflux (MII-WA-GER) frequency (B) between postprandial and fasting periods in newborns, infants, and children. ${ }^{*} P<0.05$. 
Table 3. Median and Interquartile Range (95th Percentile) of Values of Combined Multichannel Intraluminal Impedance and pH Monitoring Parameters in Postprandial and Fasting Periods

\begin{tabular}{|c|c|c|c|c|c|}
\hline Population & Reflux type & Parameters & Postprandial period & Fasting period & $P$-value \\
\hline \multirow{4}{*}{ Newborns (0-30 day) } & MII-A-GER & Frequency (GER/hr) & $0.50(0.17-1.02 ; 2.88)$ & $1.08(0.61-1.82 ; 3.12)$ & 0.002 \\
\hline & & $\mathrm{BCT}(\mathrm{sec})$ & $17.15(14.45-28.12 ; 43.88)$ & $24.88(17.06-29.73 ; 44.26)$ & 0.143 \\
\hline & MII-WA-GER & Frequency (GER/hr) & $3.43(1.47-4.83 ; 6.19)$ & $0.59(0.35-1.06 ; 1.74)$ & $<0.001$ \\
\hline & & $\mathrm{BCT}(\mathrm{sec})$ & $22.31(14.73-26.97 ; 44.72)$ & $25.49(16.62-33.06 ; 58.76)$ & 0.142 \\
\hline \multirow[t]{4}{*}{ Infants (1-12 mo) } & MII-A-GER & Frequency (GER/hr) & $0.49(0.14-1.05 ; 2.19)$ & $0.49(0.13-1.21 ; 2.64)$ & 0.679 \\
\hline & & $\mathrm{BCT}(\mathrm{sec})$ & $21.14(13.98-30.93 ; 68.31)$ & $19.54(14.30-30.89 ; 79.49)$ & 0.357 \\
\hline & MII-WA-GER & Frequency (GER/hr) & $2.21(1.30-3.58 ; 6.02)$ & $0.52(0.22-1.23 ; 1.94)$ & $<0.001$ \\
\hline & & $\mathrm{BCT}(\mathrm{sec})$ & $20.06(14.18-24.72 ; 35.49)$ & $20.00(13.69-26.45 ; 51.98)$ & 0.363 \\
\hline \multirow[t]{4}{*}{ Children (1-16 yr) } & MII-A-GER & Frequency (GER/hr) & $1.03(0.55-1.68 ; 3.85)$ & $0.19(0.01-0.32 ; 0.77)$ & $<0.001$ \\
\hline & & $\mathrm{BCT}(\mathrm{sec})$ & $22.17(16.36-30.51 ; 63.13)$ & $17.45(12.00-24.00 ; 48.57)$ & 0.355 \\
\hline & MII-WA-GER & Frequency (GER/hr) & $0.44(0.22-1.25 ; 3.86)$ & $0.37(0.12-0.77 ; 1.41)$ & $<0.001$ \\
\hline & & $\mathrm{BCT}(\mathrm{sec})$ & $19.34(11.66-25.33 ; 61.82)$ & $22.50(14.99-27.58 ; 48.33)$ & 0.223 \\
\hline \multirow{4}{*}{$\begin{array}{l}\text { Overall population } \\
\quad(0-16 \mathrm{yr})\end{array}$} & MII-A-GER & Frequency (GER/hr) & $0.65(0.20-1.35 ; 3.29)$ & $0.43(0.12-1.13 ; 2.63)$ & 0.051 \\
\hline & & $\mathrm{BCT}(\mathrm{sec})$ & $21.10(14.57-30.00 ; 58.60)$ & $19.65(13.75-29.82 ; 65.48)$ & 0.421 \\
\hline & MII-WA-GER & Frequency (GER/hr) & $1.78(0.59-3.49 ; 5.93)$ & $0.48(0.18-1.03 ; 1.75)$ & $<0.001$ \\
\hline & & $\mathrm{BCT}(\mathrm{sec})$ & $19.88(14.14-25.45 ; 43.53)$ & $21.88(14.64-30.10 ; 51.79)$ & 0.036 \\
\hline
\end{tabular}

MII, multichannel intraluminal impedance; GER, gastroesophageal reflux; MII-A-GER, MII acidic GER; MII-WA-GER, MII weakly acidic GER; BCT, bolus clearance time.

Paired $t$ test was used for statistical analysis.

Data are presented as median (interquartile range; 95 th percentile).

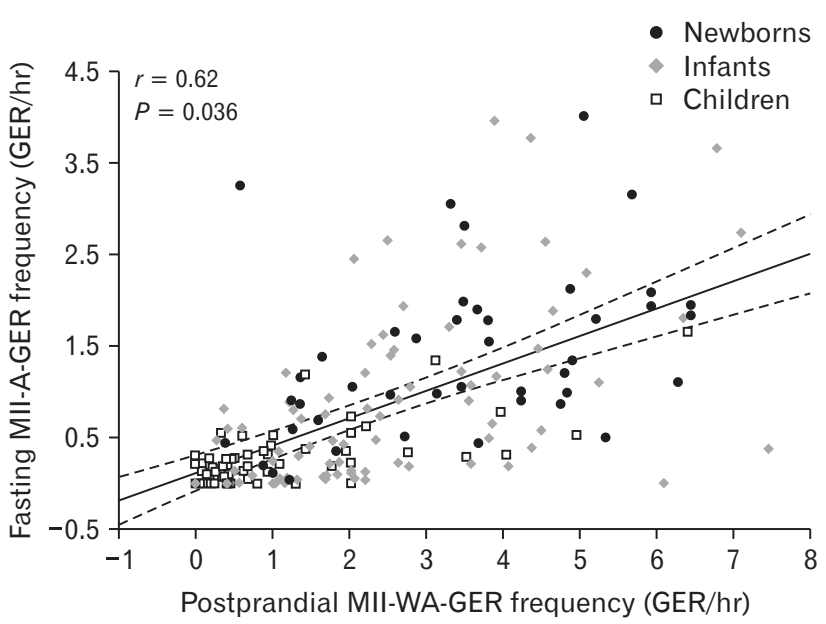

Figure 2. Relationship between fasting multichannel intraluminal impedance acidic gastroesophageal reflux (MII-A-GER) events and postprandial multichannel intraluminal impedance weakly acidic gastroesophageal reflux (MII-WA-GER) events.

cut-off considered by Mousa et al. ${ }^{20}$ Furthermore, lower RI cut offs also selected a population who is more likely to be similar to a healthy reference.

The German Pediatric Impedance Group previously published values from $700 \mathrm{MII} / \mathrm{pH}$ traces from infants and children presenting with symptoms of GER. ${ }^{19}$ However, they only provided data on
MII-GER events from a subgroup of 511 children who had confirmed pathological traces. Thus, to the best of our knowledge, ours is the first study to present $\mathrm{MII} / \mathrm{pH}$ reference values for pediatric patients, including a representative subgroup of newborns.

It has been widely demonstrated that GER characteristics and frequency vary with age. ${ }^{1,19}$ In agreement with other authors, ${ }^{19-21,25}$ our analysis confirmed that newborns have a higher frequency and longer duration of GER events, mainly secondary to a higher proportion of MII-WA-GER events, compared to infants and children. These features might be ascribed to immature esophageal peristalsis, increased inappropriate transitory lower esophageal sphincter (LES) relaxations, ${ }^{26}$ slow gastric emptying, and the significant buffering effect of milk on gastric acidity due to more frequent meals. ${ }^{25}$ Our data are consistent with those reported by López-Alonso et $\mathrm{al}^{21}$ in 21 preterm newborns fed by a modified nasogastric tube. They also observed a greater prevalence of MIIWA-GER events (median: 2.2 events/hour) than MII-A-GER events (median: 0.8 events/hour), especially during meals.

Several authors confirmed that infants with GERD experience more MII-WA-GER events and more GER events overall than children. ${ }^{13,19,25}$ The reference values for infants reported by Mousa et $\mathrm{al}^{20}$ were similar to ours in MII-ALL-GER frequency (recalculated as 2.25 events/hour), MII-A-GER frequency ( 0.83 events/ hour), MII-WA-GER frequency (1.33 events/hour), and BEI 
(1.4\%), while they found a shorter BCT (13 seconds).

In children, we found a significant, lower MII-ALL-GER and MII-WA-GER frequency, with an increase of MII-A-GER events. The change in diet, including the reduction of milk in favor of solid foods, a more competent LES, less frequent meals, and more hours in the upright position may explain this finding. The same pattern was observed by Mousa et al, ${ }^{20}$ although the MIIWA-GER, MII-MA-GER, and MII-ALL-GER frequency that we reported was 2 or 3 times higher. As a consequence, the median $\mathrm{BEI}$ in children in our study was higher than the $0.6 \%$ reported by Mousa et al, ${ }^{20}$ although no difference in BCT was observed in the 2 populations (median of 15 seconds). A possible explanation for these differences might be secondary to the different age distribution in the 2 series; indeed, we studied more pre-school children (median age 5.0 vs 7.2 years in Mousa et $\mathrm{al}^{20}$ ), whose habits are still similar to those of infants. The positive correlation between age and MII-A-GER frequency, as well as the negative correlation between age and MII-WA-GER events, supports this hypothesis: a progressive acquisition of LES competence and the progressive modification of dietary habits play a key role in the modification of the physiological pattern of GER in growing children.

MII-WALK-GER events were nearly absent in all age groups, so they were not analyzed further in our study. On this basis, we can speculate that MII-WALK-GER events could be considered a pathological finding in all pediatric ages.

Differently from other authors, ${ }^{20,21}$ we analyzed data from postprandial and fasting periods separately, as some GER symptoms occurred mainly in these periods. We found a significant reduction in MII-ALL-GER frequency in the 3 groups during fasting, while MII-A-GER frequency increased in newborns but not the other age groups. Although this finding is consistent with studies in healthy adult populations, ${ }^{16,17}$ pediatric studies focusing on postprandial GER analysis generally involved patients with GERD, ${ }^{27}$ and therefore cannot be used for comparison. This trend should be considered in the results of a $\mathrm{MII} / \mathrm{pH}$ trace: observing a higher frequency of postprandial events and rarer events during fasting periods could be representative of a physiological phenomenon, while the inverse, ie, more frequent events during the fasting period, could be considered a warning sign. Moreover, the characterisation of postprandial and fasting GER events may help individual clinical management. Patients with more fasting MII-A-GER events compared to the reference population may benefit from anti-acid therapy, whereas more postprandial MII-WA-GER is likely related to delayed gastric emptying, and might best be treated with prokinetic agents, alginate, and/or anti-regurgitation formulas.
Limitations of this study include the potential bias inherent in retrospective observational studies, as well as the a priori hypothesis of absence of pathological findings as an expression of health rather than the use of a healthy, asymptomatic population. Moreover, it might be speculated that the symptoms for which patients were referred could underlie other conditions and affect $\mathrm{MII} / \mathrm{pH}$ outcomes. However, normal values based on a voluntary, healthy pediatric population will never be available, and we argue that this limitation also represents a strength of our study. Indeed, pediatricians who perform $\mathrm{MII} / \mathrm{pH}$ would never study asymptomatic, healthy newborns, infants, or children, and they may take greater advantage of reference values based on a population that is similar to that of their patients. The observation of values that are also coherent with those of other authors ${ }^{19-21}$ reinforce the accuracy our findings. Furthermore, to limit inter-observer variability in the interpretation of $\mathrm{MII} / \mathrm{pH}$ traces, only one well-trained investigator per center reviewed the visual analysis. All used the same device and software and reached an agreement with the other investigators in case of unclear GER events.

In conclusion, we describe reference values for pediatric MII/ $\mathrm{pH}$ parameters in a large population, including newborns and infants, which support and reinforce previous evidence ${ }^{19-21}$ and provide a tool for a better interpretation of $\mathrm{MII} / \mathrm{pH}$. In addition, this study highlights the changing physiological pattern of GER during growth, characterized by more MII-WA-GER events in younger patients and in postprandial periods. We believe that our findings might help fill existing gaps to allow for more standardized analyses of $\mathrm{MII} / \mathrm{pH}$ results, and we advocate their routine use.

Acknowledgements: The authors would like to thank Ms Trudy Perdrix-Thoma for editing assistance and English language review.

Financial support: None.

\section{Conflicts of interest: None.}

Author contributions: Francesco Cresi, Silvia Salvatore, and Ruggiero Francavilla were the principal investigators in the 3 centers involved (Neonatal/Pediatric Gastroenterology Services of Sant'Anna Hospital - Turin, Italy; Giovanni XXIII Hospital - Bari, Italy; and Del Ponte Hospital -Varese, Italy): designed the study and coordinated the collection of data; Fernanda Cristofori, Antonio Ripepi, and Elena Maggiora: performed the MII/pH monitoring; Francesco Cresi, Silvia Salvatore, and Ruggiero Francavilla reviewed the $\mathrm{MII} / \mathrm{pH}$ traces; Elena Andrea Cester and Domenico 
Umberto De Rose: wrote the first draft of the manuscript; Francesco Cresi and Elena Andrea Cester: performed the statistical analysis; and Francesco Cresi, Elena Andrea Cester, Silvia Salvatore, Anna Maria Magistà, Claudia Fontana, Elena Maggiora, Alessandra Coscia, and Fernanda Cristofori: revised the manuscript. All the authors approved the final version of the manuscript as submitted.

\section{References}

1. Vandenplas Y, Rudolph CD, Di Lorenzo C, et al. Pediatric gastroesophageal reflux clinical practice guidelines: joint recommendations of the North American Society for Pediatric Gastroenterology, Hepatology, and Nutrition (NASPGHAN) and the European Society for Pediatric Gastroenterology, Hepatology, and Nutrition (ESPGHAN). J Pediatr Gastroenterol Nutr 2009;49:498-547.

2. Canani RB, Cirillo P, Roggero $P$, et al. Therapy with gastric acidity inhibitors increases the risk of acute gastroenteritis and community-acquired pneumonia in children. Pediatrics 2006;117:e817-e820.

3. Terrin G, Passariello A, De Curtis M, et al. Ranitidine is associated with infections, necrotizing enterocolitis, and fatal outcome in newborns. Pediatrics 2012;129:e40-e45.

4. Cresi F, Marinaccio C, Russo MC, Miniero R, Silvestro L. Short-term effect of domperidone on gastroesophageal reflux in newborns assessed by combined intraluminal impedance and $\mathrm{pH}$ monitoring. J Perinatol 2008;28:766-770.

5. Mühlbauer B, Janhsen K, Pichler J, Schoettler P. Off-label use of prescription drugs in childhood and adolescence: an analysis of prescription patterns in Germany. Dtsch Ärzteblatt Int 2009;106:25-31.

6. De Rose DU, Cresi F, Romano V, et al. Can MII-pH values predict the duration of treatment for GERD in preterm infants? Early Hum Dev 2014;90:501-505.

7. Singendonk MM, Benninga MA, van Wijk MP. Reflux monitoring in children. Neurogastroenterol Motil 2016;28:1452-1459.

8. Wenzl TG, Skopnik H. Intraluminal impedance: an ideal technique for evaluation of pediatric gastroesophageal reflux disease. Curr Gastroenterol Rep 2000;2:259-264.

9. Loots CM, van Wijk MP, Blondeau $\mathrm{K}$, et al. Interobserver and intraobserver variability in $\mathrm{pH}$-impedance analysis between 10 experts and automated analysis. J Pediatr 2012;160:441-446, e1.

10. Corvaglia L, Zama D, Gualdi S, Ferlini M, Aceti A, Faldella G. Gastrooesophageal reflux increases the number of apnoeas in very preterm infants. Arch Dis Child Fetal Neonatal Ed 2009;94:F188-F192.

11. Slocum C, Arko M, Di Fiore J, Martin RJ, Hibbs AM. Apnea, bradycardia and desaturation in preterm infants before and after feeding. $\mathrm{J}$ Perinatol 2009;29:209-212.

12. Di Fiore JM, Arko M, Whitehouse M, Kimball A, Martin RJ. Apnea is not prolonged by acid gastroesophageal reflux in preterm infants. Pediatrics 2005;116:1059-1063.

13. Cresi F, Martinelli D, Maggiora E, et al. Cardiorespiratory events in infants with gastroesophageal reflux symptoms: is there any association?
Neurogastroenterol Motil 2018;30:e13278.

14. Francavilla R, Magistà AM, Bucci N, et al. Comparison of esophageal $\mathrm{pH}$ and multichannel intraluminal impedance testing in pediatric patients with suspected gastroesophageal reflux. J Pediatr Gastroenterol Nutr 2010;50:154-160.

15. Wenzl TG, Benninga MA, Loots CM, Salvatore S, Vandenplas Y;ESPGHAN EURO-PIG Working Group. Indications, methodology, and interpretation of combined esophageal impedance-pH monitoring in children: ESPGHAN EURO-PIG standard protocol. J Pediatr Gastroenterol Nutr 2012;55:230-234.

16. Shay S, Tutuian R, Sifrim D, et al. Twenty-four hour ambulatory simultaneous impedance and $\mathrm{pH}$ monitoring: a multicenter report of normal values from 60 healthy volunteers. Am J Gastroenterol 2004;99:1037-1043.

17. Zerbib F, des Varannes SB, Roman S, et al. Normal values and day-today variability of 24-h ambulatory oesophageal impedance-pH monitoring in a Belgian-French cohort of healthy subjects. Aliment Pharmacol Ther 2005;22:1011-1021.

18. Zentilin P, Iiritano E, Dulbecco P, et al. Normal values of 24-h ambulatory intraluminal impedance combined with $\mathrm{pH}$-metry in subjects eating a Mediterranean diet. Dig Liver Dis 2006;38:226-232.

19. Pilic D, Fröhlich T, Nöh F, et al. Detection of gastroesophageal reflux in children using combined multichannel intraluminal impedance and $\mathrm{pH}$ measurement: data from the German pediatric impedance group. J Pediatr 2011;158:650-654, e1.

20. Mousa H, Machado R, Orsi M, et al. Combined multichannel intraluminal impedance-pH (MII-pH): multicenter report of normal values from 117 children. Curr Gastroenterol Rep 2014;16:400.

21. López-Alonso M, Moya MJ, Cabo JA, et al. Twenty-four-hour esophageal impedance-pH monitoring in healthy preterm neonates: rate and characteristics of acid, weakly acidic, and weakly alkaline gastroesophageal reflux. Pediatrics 2006;118:e299-e308.

22. Quitadamo P, Tambucci R, Mancini V, et al. Esophageal $\mathrm{pH}$-impedance monitoring in children: position paper on indications, methodology and interpretation by the SIGENP working group. Dig Liver Dis 2019;51:1522-1536.

23. Strobel CT, Byrne WJ, Ament ME, Euler AR. Correlation of esophageal lengths in children with height: application to the tuttle test without prior esophageal manometry. J Pediatr 1979;94:81-84.

24. Cresi F, Locatelli E, Marinaccio C, Grasso G, Coscia A, Bertino E. Prognostic values of multichannel intraluminal impedance and $\mathrm{pH}$ monitoring in newborns with symptoms of gastroesophageal reflux disease. J Pediatr 2013;162:770-775.

25. Loots CM, Benninga MA, Davidson GP, Omari TI. Addition of $\mathrm{pH}-$ impedance monitoring to standard $\mathrm{pH}$ monitoring increases the yield of symptom association analysis in infants and children with gastroesophageal reflux. J Pediatr 2009;154:248-252.

26. Omari TI, Miki K, Davidson G, et al. Characterisation of relaxation of the lower oesophageal sphincter in healthy premature infants. Gut 1997;40:370-375.

27. Sifrim D, Holloway R, Silny J, Tack J, Lerut A, Janssens J. Composition of the postprandial refluxate in patients with gastroesophageal reflux disease. Am J Gastroenterol 2001;96:647-655. 